DOI: $10.17805 /$ ggz.2019.2.5

\title{
Соотношение потребностей субъъекта деятельности и тезауруса
}

О. В. Долженкова

Институт философии и права СО РАН, г. Новосибирск

В статье, подготовленной на основе доклада на III Академических чтениях памяти Вл. А. Лукова «Тезаурусы и проблемы культуры» (МосГУ, 4 апреля 2019 г.), рассматривается соотношение тезауруса и потребностей субъекта в системе ориентаџий деятельности. На основе сопоставления понятия о тезаурусе, его структуре и содержании с представлением о сущности явления потребностей и их классификаиии делается вывод об амбивалентной природе тезауруса: его зависимости от потребностей роста и влиянии на формирование индивидуальной диспозиции потребностей, в соответствии с которой обеспечивается реализация потребности в самосохранении.

Ключевые слова: тезаурус; картина мира; потребности; потребности сохранения; потребности роста; предметные потребности; функциональные потребности; потребность в самосохранении; деятельность; субъект деятельности; ориентация деятельности

\section{Correlation between the Needs of the Actor and Thesaurus O. V. Dolzhenkova Institute of Philosophy and Law, Siberian Branch, Russian Academy of Sciences, Novosibirsk}

The article draws on a paper presented at the 3rd Academic Readings in the Memory of Vladimir A. Lukov "Thesauri and Issues of Culture" (Moscow University for the Humanities, April 4, 2019). It examines the correlation between thesaurus and the needs of the subject in the system of activity orientation. The author juxtaposes the concept of thesaurus, its structure and content with the insight into the essence of the phenomenon of needs and their classification. She makes a conclusion about the ambivalent nature of thesaurus: its dependence on the need for advancement and its influence on the development of an individual disposition of needs, in accordance with which the need for self-preservation is being realized.

Keywords: thesaurus; world view; needs; needs for preservation; needs for growth; objective needs; functional needs; need for self-preservation; activity; subject of activity; orientation of activity 
В работах, посвященных исследованию потребностей и тезауруса, неоднократно отмечается, что оба эти явления оказывают влияние на ориентацию деятельности. Так, согласно Т. Парсонсу, в системе ориентации субъекта деятельности одним из регуляторов выступают потребности. Соответственно, он выделяет мотивационный вид ориентации субъекта (Парсонс, 2002: 467-470). Отечественными и зарубежными психологами неоднократно отмечалось, что потребность является источником активности. По Г. Мюррею, потребность - это гипотетическая внутренняя сила организма, которая вызывает активность (Murray, 1938: 42, 58, 60, 64). Как отмечал Д. Н. Узнадзе, «потребность можно квалифицировать всякое состояние психофизического организма, который, нуждаясь в изменениях окружающей среды, дает импульсы к необходимой для этой цели активности» (Узнадзе, 2001: 43), является источником активности (Узнадзе, 2004: 120). Возникновение потребности, как указывает Е. П. Ильин, - это механизм, который запускает активность человека на поиск и достижение цели (Ильин, 2002: 35-37).

Тезаурус также принято рассматривается как механизм, с помощью которого индивид ориентируется в окружающем мире. Так, тезаурус рассматривается как ориентационный комплекс, основная функция которого заключается в обеспечении взаимодействия субъекта с окружающей средой, его ориентацию в окружающей среде (Луков, 2010; Осокина, 2011: 179; Ламажаа, 2012: 28; Луков В., Луков Вл., 2013а: 107).

Для тезауруса как механизма ориентации субъекта можно, как представляется, выделить несколько особенностей функционирования. Во-первых, принято подчеркивать когнитивную, связанную с познанием природу тезауруса. Так, в концепции языковой личности Ю. Н. Караулова тезаурусом называется ее средний лингво-когнитивный уровень, под которым понимается иерархия смыслов и ценностей, отраженная в языковой картине мира личности (Караулов, 2010: 36-37). Термином «тезаурус» принято обозначать: определенное накопленное и структурированное представление индивида об окружающей его действительности (Шрейдер, Шаров, 1982: 117; Осокина, 2011: 179; Луков В., Луков Вл., 2013b: 4); так называемую априорную информацию, которой обладает субъект деятельности (Кремянский, 1977: 29-30; Кузнецов, Мусхелишвили, Шрейдер, 1999: 84). Причем разнообразие зафиксированной в тезаурусе априорной информации определяется разнообразием взаимодействий субъекта со средой (Афанасьев, 2013: 115-116).

Во-вторых, тезаурус представляет собой проявление сходства субъектов информационного взаимодействия и является условием осуществления взаимодействия как такового (Коган, 1980: 101; Кузнецов, Мусхелишвили, Шрейдер, 1999: 84). Тезаурус позволяет субъекту осуществлять интерпретацию и понимание получаемой извне информации и, таким образом, влияет на про- 
цесс приема (декодирование) и обработки информации (усвоения) (Кремянский, 1977: 29-30; Кузнецов, Мусхелишвили, Шрейдер, 1999: 84). Данная особенность тезауруса субъекта определяет его способность осуществлять процессы управления, направленные на обеспечение жизнедеятельности обладающего тезаурусом субъекта.

Как отмечает В.Г. Афанасьев, управление является переработкой информации в сигналы, направляющие деятельность самоуправляющихся систем. Функции управления состоят в том, чтобы блокировать те элементы многообразия, которые могут нарушить нормальное функционирование системы или разрушить ее, и пропускать, ассимилировать те элементы среды (разнообразия), которые полезны системе, т. е. способствуют сохранению ее качественной определенности, нормальному функционированию, совершенствованию и развитию. Процессы управления, по сути, направлены на поддержание жизнедеятельности принимающей сигналы системы. И реакция со стороны субъектов информационного взаимодействия должна происходить только на ту информацию, которая соответствует их природе и необходима для обеспечения их жизнедеятельности (Афанасьев, 2013: 112, 115). Таким образом, функционирование тезауруса связано с реализацией потребности в самосохранении, а также, очевидно, других потребностей субъекта.

Потребность можно определить как свойство субъекта, выраженное в наличии у него определенного алгоритма (программы), содержанием которого, является сигнализирование субъекту о состоянии нужды при помощи перевода объективного состояния напряжения организма, возникшего в результате отношений субъекта с окружающей средой, в субъективное психическое состояние (Дилигенский, 1976: 31-32; Ильин, 2002: 35-37).

Выделяют две большие категории потребностей: потребности сохранения и потребности роста (развития) (Симонов, 1987: 51). К потребностям роста можно отнести так называемые исследовательские потребности. И поскольку тезаурус является механизмом категоризации внешнего по отношению к субъекту мира, поэтому его формирование и функционирование обусловлено потребностями роста.

Итак, формирование и функционирование тезауруса обусловлено потребностями роста. Однако потребности роста, согласно выделенному А. Маслоу принципу целостности личности (Маслоу, 2008: 46), не являются самодостаточной системой, а встроены в систему личности, а значит, направлены на реализацию основной цели - осуществления самосохранения субъекта деятельности. Формирование тезауруса под воздействием потребностей роста еще раз подтверждает предположение о том, что функционирование тезауруса направлено на обеспечение самосохранения субъекта, т. е. должно 
обеспечивать реализацию тех потребностей, которые смогут реализовать в определенных условиях потребность в самосохранении.

Помимо потребностей роста у человека, как и у других живых существ, существуют потребности сохранения. К потребностям сохранения можно отнести два вида потребностей: органические и так называемые организационные. Органические потребности являются, если применить здесь классификацию Д. Н. Узнадзе (Узнадзе, 2001: 44-45), по своему происхождению потребностями предметными, субстанциональными. Органические и соответственно предметные потребности могут обеспечить реализацию потребности в самосохранении только в очень урезанном виде: в небольшой временной перспективе, поскольку не обеспечивают сохранение других особей данного вида.

Организационные потребности сохранения связаны с необходимостью в обеспечении коллективного способа жизнедеятельности, поэтому они являются в большинстве своем потребностями в определенной деятельности, т. е. потребностями функциональными. Очевидно, что по своей природе организационные потребности направлены на выживание не одной особи, а группы особей одного вида. Поэтому они способны обеспечить осуществление самосохранения в более длительной, чем предметные потребности, временной перспективе.

Однако нужно отметить, что функциональные потребности могут реализовываться и предметным способом. Подобное изменение способа удовлетворения потребности свидетельствует о сокращении временной перспективы, на которую ориентирует субъекта потребность, и, соответственно, об ослаблении реализации потребности в самосохранении.

Для человека свойственны специфические для него родовые потребности. Особенность родовых потребностей человека заключается в том, что, имея свои предпосылки в животном мире, они окончательно формируются в процессе социализации, т. е. в процессе деятельности субъекта и его взаимодействия с другими субъектами. Иными словами, родовые потребности человека являются производными от родовых для человека видов деятельности (Момджян, 2015: 4), а социальная среда в целом служит катализатором появления у субъекта новых потребностей, связанных с новыми видами деятельности.

Еще одна особенность родовых потребностей человека состоит в том, что они направлены на обязательное воспроизводство организационных потребностей сохранения, отвечающих за коллективный образ жизни, а также потребностей роста, которые, как и организационные потребности сохранения, являются по происхождению функциональными потребностями. Причем, как отмечает Б. Малиновский, специфические для человека потребно- 
сти, или как он их называет, культурные или инструментальные императивы, не менее обязательны для реализации, чем его органические потребности (Малиновский, 2005: 103-105). Таким образом, реализация потребности в самосохранении человека определяется в первую очередь функциональными, а не предметными потребностями.

Тезаурус, как уже отмечалось, формируется путем взаимодействия субъекта деятельности с внешней средой. Он представляет собой своего рода фильтр для получения информации в виде картины мира, когнитивной карты, которая ориентирует деятельность субъекта. Значение осуществляемой тезаурусом ориентации субъекта заключается, в частности, в обеспечении индивида знаниями о том, какие именно способы деятельности в данной конкретной среде помогут осуществить реализацию его потребности в самосохранении. Соответственно, формируются и актуализируются определенные потребности в осуществлении деятельности определенного типа.

Поэтому не вполне верным представляется замечание Ю. Н. Караулова о том, что мотивационный уровень в структуре языковой личности играет главную роль в иерархии уровней языковой личности (Караулов, 2010: 211). И можно согласиться с мнением С. А. Осокиной, подчеркивающей влияние тезауруса на остальные уровни языковой личности, в том числе и на мотивационный уровень (Осокина, 2011: 180-181).

Таким образом, соотношение тезауруса и потребностей в области ориентации и регулирования деятельности субъекта характеризуется их взаимовлиянием. Тезаурус представляет собой один из механизмов реализации потребностей роста субъекта. Но в свою очередь, на основе категоризации опыта взаимодействий субъекта с внешним миром, тезаурус является фактором формирования индивидуальной диспозиции потребностей, в соответствии с которой обеспечивается их удовлетворение и, в конечном итоге, реализация потребности в самосохранении.

\section{СПИСОК ЛИТЕРАТУРЫ}

Афанасьев, В. Г. (2013) Социальная информация и управление обществом. М. : Книжный дом «ЛИБРОКОМ». 408 с.

Дилигенский, Г. Г. (1976) Проблемы теории человеческих потребностей // Вопросы философии. № 9. С. 30-43.

Ильин, Е. П. (2002) Мотивация и мотивы. СПб. : Питер. 512 с.

Караулов, Ю. Н. (2010) Русский язык и языковая личность. М. : Издательство ЛКИ. 264 с.

Коган, В. 3. (1980) Информационное взаимодействие (опыт анализа субъективно-объективных отношений). Томск : Изд-во Томского ун-та. 194 с. 
Кремянский, В. И. (1977) Методологические проблемы системного подхода к информации. М. : Наука. 287, [1] с.

Кузнецов, Н. А., Мусхелишвили, Н. Л., Шрейдер, Ю. А. (1999) Информационное взаимодействие как объект научного исследования (перспективы информатики) // Вопросы философии. № 1. С. 77-87.

Ламажаа, Ч. К. (2012) Тезаурусный подход к анализу тувинской культуры // Новые исследования Тувы. № 1. С. 25-46.

Луков, В. А., Луков, Вл. А. (2013а) Тезаурус как ориентационный комплекс // Знание. Понимание. Умение. № 2. С. 107-110.

Луков, В. А., Луков, Вл. А. (2013b) Тезаурусный подход в гуманитарном знании // Тезаурусный анализ мировой культуры : сб. науч. трудов. Вып. 25. М. : Изд-во Моск. гуманит. ун-та. 160 с. С. 3-13.

Луков, Вл. А. (2010) Народная культура и цивилизационная культура // Знание. Понимание. Умение. № 2. С. 268-271.

Малиновский, Б. (2005) Научная теория культуры. М. : ОГИ. 184 с.

Маслоу, А. (2008) Мотивация и личность. СПб. : Питер. 352 с.

Момджян, К. Х. (2015) Универсальные потребности и родовая сущность человека // Вопросы философии. № 2. С. 3-13.

Осокина, С. А. (2011) Индивидуальный тезаурус как система знаний: соотношение понятий «индивидуальный тезаурус» и «языковая личность» // Знание. Понимание. Умение. № 4. С. 178-183.

Парсонс, Т. (2002) О структуре социального действия. М. : Академический проект. 880 с.

Симонов, П. В. (1987) Мотивированный мозг. Высшая нервная деятельность и естественнонаучные основы общей психологии. М. : Наука. 270 с.

Узнадзе, Д. Н. (2001) Психология установки. СПб. : Питер. 416 с.

Узнадзе, Д. Н. (2004) Общая психология. М. : Смысл ; СПб. : Питер. 413 c.

Шрейдер, Ю. А., Шаров, А. А. (1982) Системы и модели. М. : Радио и связь. 152 с.

Murray, H. A. (1938) Explorations in personality : A clinical and experimental study of fifty men of college age by the workers at the Harvard Psychological Clinic. N. Y. : Oxford University Press. xiv, 761 p.

Дата поступления: 20.04.2019 г.

\section{REFERENCES}

Afanasiev, V. G. (2013) Sotsial'naia informatsiia $i$ upravlenie obshchestvom [Social information and governance of society]. Moscow : Book House "LIBROKOM”. 408 p. (In Russ.). 
Diligenskii, G. G. (1976) Problemy teorii chelovecheskikh potrebnostei [Issues of the theory of human needs]. Voprosy filosofii, no. 9, pp. 30-43. (In Russ.).

Ilyin, E. P. (2002) Motivatsiia $i$ motivy [Motivation and motives]. St. Petersburg : Piter Publ. 512 p. (In Russ.).

Karaulov, Yu. N. (2010) Russkii iazyk i iazykovaia lichnost' [The Russian language and lingual personality]. Moscow : LKI Publ. 264 p. (In Russ.).

Kogan, V. Z. (1980) Informatsionnoe vzaimodeistvie (opyt analiza sub"ektivno-ob"ektivnykh otnoshenii) [Informational interaction (An attempt of analysis of subjective and objective relations]. Tomsk : Tomsk University Publ. 194 p. (In Russ.).

Kremianskii, V. I. (1977) Metodologicheskie problemy sistemnogo podkhoda $k$ informatsii [Methodological issues of the systematic approach to information]. Moscow : Nauka Publ. 287, [1] p. (In Russ.).

Kuznetsov, N. A., Muskhelishvili, N. L. and Shreider, Yu. A. (1999) Informatsionnoe vzaimodeistvie kak ob"ekt nauchnogo issledovaniia (perspektivy informatiki) [Informational interaction as an object of scientific research (Prospects of informatics)]. Voprosy filosofii, no. 1, pp. 77-87. (In Russ.).

Lamazhaa, Ch. K. (2012) Tezaurusnyi podkhod k analizu tuvinskoi kul'tury [Thesaurus approach to analysis of the Tuvan culture]. Novye issledovaniia Tuvy, no. 1, pp. 25-46. (In Russ.).

Lukov, V. A. and Lukov, Vl. A. (2013a) Tezaurus kak orientatsionnyi kompleks [The thesaurus as an orientation complex]. Znanie. Ponimanie. Umenie, no. 2, pp. 107-110. (In Russ.).

Lukov, V. A. and Lukov, Vl. A. (2013b) Tezaurusnyi podkhod v gumanitarnom znanii [Thesaurus approach in the humanities knowledge]. In: Tezaurusnyi analiz mirovoi kul'tury [The thesaurus analysis of world culture] : A collection of research articles. Issue 25 / ed. by Vl. A. Lukov. Moscow : Moscow University for the Humanities Publ. 160 p. Pp. 3-13. (In Russ.).

Lukov, Vl. A. (2010) Narodnaia kul'tura i tsivilizatsionnaia kul'tura [Folk culture and civilizational culture]. Znanie. Ponimanie. Umenie, no. 2, pp. 268-271. (In Russ.).

Malinowski, B. (2005) Nauchnaia teoriia kul'tury [A scientific theory of culture]. Moscow : OGI Publ. 184 p. (In Russ.).

Maslow, A. (2008) Motivatsiia $i$ lichnost' [Motivation and personality]. St. Petersburg : Piter Publ. 352 p. (In Russ.).

Momdzhyan, K. Kh. (2015) Universal'nye potrebnosti i rodovaia sushchnost' cheloveka [Universal needs and a generic human essence]. Voprosy filosofii, no. 2, pp. 3-13. (In Russ.).

Osokina, S. A. (2011) Individual'nyi tezaurus kak sistema znanii: sootnoshenie poniatii «individual'nyi tezaurus» i «iazykovaia lichnost'»[Individual 
thesaurus as a system of knowledge: The correlation of notions "individual thesaurus" and "language personality"]. Znanie. Ponimanie. Umenie, no. 4, pp. 178-183. (In Russ.).

Parsons, T. (2002) O strukture sotsial'nogo deistviia [The structure of social Action]. Moscow : Akademicheskii proekt Publ. 880 p. (In Russ.).

Simonov, P. V. (1987) Motivirovannyi mozg. Vysshaia nervnaia deiatel'nost' $i$ estestvennonauchnye osnovy obshchei psikhologii [Motivated brain. Higher nervous activity and scientific foundations of general psychology]. Moscow : Nauka Publ. 270 p. (In Russ.).

Uznadze, D. N. (2001) Psikhologiia ustanovki [Psychology of mental set]. St. Petersburg : Piter Publ. 416 p. (In Russ.).

Uznadze, D. N. (2004) Obshchaia psikhologiia [General psychology]. Moscow : Smysl Publ. ; St. Petersburg : Piter Publ. 413 p. (In Russ.).

Shreider, Yu. A. and Sharov, A. A. (1982) Sistemy i modeli [Systems and models]. Moscow : Radio i sviaz' Publ. 152 p.

Murray, H. A. (1938) Explorations in personality : A clinical and experimental study of fifty men of college age by the workers at the Harvard Psychological Clinic. New York : Oxford University Press. xiv, 761 p.

Submission date: 20.04.2019.

Должсенова Ольга Викторовна - аспирант Института философии и права Сибирского отделения Российской академии наук (Новосибирск). Адpec: 630090, г. Новосибирск, ул. Николаева, 8. Тел./факс: +7 (383) 330-09-75. Эл. адрес: afonasin@post.nsu.ru

Dolzhenkova Olga Viktorovna, Postgraduate Student, Institute of Philosophy and Law, Siberian Branch, Russian Academy of Sciences. Postal address: 8 Nikolaeva St., 630090 Novosibirsk, Russian Federation. Tel.: +7 (383) 330-09-75. Email: afonasin@post.nsu.ru

Для цитирования:

Долженкова О. В. Соотношение потребностей субъекта деятельности и тезауруса [Электронный ресурс] // Горизонты гуманитарного знания. 2019. № 2. C. 72-79. URL: http://journals.mosgu.ru/ggz/article/view/1005 (дата обращения: дд.мм.гггг). DOI: $\underline{10.17805 / \mathrm{ggz} .2019 .2 .5}$ 